\title{
A COMUNICAÇÃO ORGANIZACIONAL \\ CULTURAL E AFETIVA: UMA REFLEXÃO DAS RELAÇÕES DE TRABALHO CRIATIVA NO CONTEXTO DA ECONOMIA CRIATIVA
}

\author{
CAROLINE DELEVATI COLPO \\ UNIVERSIDADE FEEVALE \\ PORTO ALEGRE, RIO GRANDE DO SUL, BRASIL \\ E-MAIL: CAROLINECOLPO@GMAIL.COM
}


A COMUNICAÇÃO ORGANIZACIONAL CULTURAL E AFETIVA: UMA REFLEXÃO DAS RELAÇÕES DE TRABALHO CRIATIVA NO CONTEXTO DA ECONOMIA CRIATIVA

Resumo: Este trabalho tem o objetivo de investigar, no contexto da economia criativa, a comunicação organizacional cultural e afetiva como elemento das relações de trabalho criativas nas organizações. Com caráter qualitativo, aplica-se a técnica de pesquisa bibliográfica. Este estudo tem sua relevância pois contribui na reflexão sobre as relação de pessoas criativas nos contextos organizacionais, permeadas pela sua cultura e sua afetividade como forma de potencialização da economia criativa.

Palavras chaves: economia criativa; comunicação organizacional; cultura; afetividade.

THE CULTURAL AND AFFECTIVE ORGANIZATIONAL COMMUNICATION: A REFLECTION ON THE LABOR RELATIONS CREATIVE IN THE CONTEXT OF THE CREATIVE ECONOMY

Abstract: This work aims to investigate, within the context of the creative economy, the cultural and affective organizational communication as an element of creative labor relations in organizations. With feature qualitative, the researcher applies a literature technique. This study has its relevance as it helps in thinking about the relationship of creative people in organizational contexts. Those relationships are permeated by the culture and affection of the creative people leveraging the creative economy.

Keywords: creative economy; organizational communication; culture; affectivity.

LA COMUNICACIÓN ORGANIZACIONAL CULTURAL Y AFECTIVA: UNA REFLEXIÓN SOBRE LAS RELACIONES DE TRABAJO CREATIVO EN EL CONTEXTO DE LA ECONOMÍA CREATIVA

Resumen: Ese trabajo tiene como objetivo investigar en el contexto de la economía creativa, la comunicación organizacional cultural y afectiva como parte de las relaciones laborales en las organizaciones creativas. Com aspectos cualitativo, se aplica a la técnica de búsqueda bibliográfica. Este estudio tiene su importancia, ya que ayuda en la reflexión sobre la relación de las personas creativas en contextos organizacionales, impregnado de su cultura y el afecto como una forma de aprovechar la economía creativa.

Palabras clave: economía creativa; comunicación organizacional; cultura; afectividad. 


\section{CONTEXTUALIZANDO AS POSSIBILIDADES DE COMPREENSÃO DA PESQUISA}

A apropriação do conceito de comunicação organizacional está, constantemente, tomando formas e entendimentos diferentes em decorrência das diversas maneiras que os processos comunicacionais estão se estruturando na evolução da sociedade. Por muito tempo, as pesquisas se detiveram em pensar e estruturar a comunicação como midiática e mediada por instrumentos, ferramentas e veículos. Esta interação entre os sujeitos e os meios/ ferramentas/instrumentos tem significados importantes nos processos de comunicação, principalmente para as organizações que destinam parte do seu tempo para se relacionar com os públicos. Porém, neste contexto, o entendimento da comunicação sujeito-sujeito nem sempre é considerado para a construção e reconstrução das relações criativas dos sujeitos organizacionais. No contexto organizacional as relações criativas podem acontecer no espaço de trocas de afetividades. Essas afetividades, que podem ser tanto divergentes como convergentes, estão relacionadas às criatividades dos indivíduos que interagem através do clima de diálogo e estímulo à participação na estrutura organizacional flexível. Isto permite que a cultura e afetividade dos indivíduos possam ter espaço de manifestações no contexto organizacional.

Em algumas organizações, com características de relações mais flexíveis, tanto no trabalho, como nas hierarquias organizacionais, nem sempre os processos de comunicação são consolidados, apenas, por meios/ferramentas/instrumentos. Isto porque, estas organizações perceberam que nem sempre as informações - transmissão de dados - são efetivamente comunicada pelos instrumentos, tendo em vista que cada receptor gera significados para aquilo que deseja. Para Anzieu e Martin (1971) toda atividade social (lembrando de que as relações organizacionais são um lugar no qual se efetiva a atividade social) implica um intercâmbio de informações, quer seja entre os membros de um mesmo grupo, quer seja entre os membros de grupos diferentes. Os autores alertam para o fato que o processo de interação entre os sujeitos se efetiva nos grupos através da comunicação, ou seja, a captação de informações úteis e eficazes, e o uso, ou não, dessas mesmas informações.

Com isto, não há um pressuposto básico consolidado para a manutenção da comunicação organizacional, tendo em vista que estas organizações se 
A comunicação organizacional cultural e afetiva: uma reflexão das relações de trabalho criativa no contexto da economia criativa

reconstroem a cada momento em que o seu contexto social, se reestrutura com base nos seus sujeitos que a integram. Associado e este fator tem-se a uma característica marcante do novo mercado de trabalho no qual, segundo Florida (2002), as pessoas criativas e, consequentemente mais produtivas, não ficam mais amarradas as organizações por muito tempo. Em vez de ascender profissionalmente em uma única organização, elas se movem lateralmente de organização para organização em busca do que almejam. Sendo assim, este estudo tem o objetivo de investigar, no contexto da economia criativa, a comunicação organizacional cultural e afetiva como elemento das relações de trabalho criativas nas organizações.

\section{COMUNICAÇÃO ORGANIZACIONAL SUAS CULTURAS E AFETIVIDA- DES}

No mundo contemporâneo há um aumento significativo de novas organizações que surgem para atender às crescentes demandas sociais e mercadológicas, desencadeadas, muitas vezes, pela perspicácia dos agentes do mercado competitivo, os quais estão atentos às oportunidades e às ameaças do ambiente global e organizacional. Estas organizações podem ser vistas como sistemas vivos que se constituem de partes interdependentes entre si, que interagem e se transformam mutuamente no todo. Sob esta perspectiva, a noção de organização necessita ser percebida como viva, capaz de transformar e de ser transformada através das relações que estabelece com a sociedade (MORIN, 1991).

Já Lapassade (1989) define organizações com pelo menos dois significados. Por um lado, designa um ato organizador que é exercido pelos sujeitos, como por exemplo, a organização de processos administrativos ou o ato e efeito de organizar, que pode ser uma das funções da administração. Por outro lado, o autor define organização como referente às realidades sociais ou à organização de uma coletividade instituída com vistas a objetivos definidos, à combinação de esforços para atingir propósitos coletivos, como uma entidade social em busca de interesses coletivos, ou ainda como um agrupamento planejado de pessoas que desempenham funções e trabaIham conjuntamente para atingir objetivos comuns. É com base no entendimento de Morin (1991) e na segunda concepção de organização sugerida por Lapassade (1989) que este trabalho se apoia para as reflexões.

Para Srour (1998), estas organizações podem ser definidas como coletividades especializadas na produção de um determinado bem ou serviço, 
combinando agentes sociais e recursos e, posteriormente, convertendo-se em instrumento de "economia de esforço" (SROUR, 1998, p. 107). Podem ser consideradas, ainda segundo Srour (1998), como sistemas abertos que constitui-se de partes interdependentes, que interagem e transformam-se mutuamente, além de campos de forças que competem entre si para absorver energia do ambiente externo, processar insumos e gerar produtos. Para isto, é necessário administrar pressões e fomentar grupos de apoios para criar credibilidade junto à sociedade. Neste sentido torna-se importante a capacidade de adaptação e flexibilidade das organizações.

No conceito sugerido por Srour (1998), os indivíduos estão imersos em organizações, tanto como parte potencial das ações organizacionais como também dependentes dessas ações. Os sujeitos nascem e morrem dentro de organizações e durante a vida se relacionam com uma infinidade delas. Estabelece-se aqui, um sistema recursivo complexo para o entendimento das relações individuais com as organizações. Da mesma forma que elas produzem o indivíduo, também são produzidas por este. Mas, ainda pode-se refletir de forma hologramática que ao mesmo tempo em que o individuo é um todo, tem a organização como sua parte, ou esta é o todo tendo o indivíduo como sua parte.

Entretanto, nem sempre os indivíduos foram considerados partes importantes para as organizações. Por muito tempo as organizações foram consideradas conjuntos estabelecidos, estabilizados e racionais, tendo por objetivo apenas produção de bens e serviços. A concepção de uma organização racional, em busca de resultados preestabelecidos, compara as organizações com máquinas, cujas diversas engrenagens (humanas ou técnicas) podem ser facilmente substituídas, prevendo a melhor articulação possível com os menores custos possíveis. Sob este olhar, a vida organizacional torna-se repleta de rotinas, como um relógio (ENRIQUEZ, 1997). As organizações são planejadas à imagem das máquinas e esperam dos empregados comportamentos mecânicos. Adotam modelos de gestão fundamentados em ciclos, envolvendo o planejamento, a execução, o controle e a avaliação das ações. Observa- se o uso maciço de ferramentas, do tipo check list, para melhorar os processos organizacionais (MORGAN, 2000).

Com o tempo, as organizações passaram a ser entendidas, pela sociologia das organizações, como um sistema social e humano mediado por interesses políticos. Decisões, participação no poder e controle de atividades tornaram-se, tanto para administradores quanto para analistas das estrutu- 
A comunicação organizacional cultural e afetiva: uma reflexão das relações de trabalho criativa no contexto da economia criativa

ras sociais, preocupações centrais na vida organizacional (ENRIQUEZ, 1997). Neste contexto, os sistemas de atividades políticas, dentro das organizações, podem ser claramente manifestados nos conflitos e jogos de poder e nas intrigas interpessoais que resultam do fluxo da atividade organizacional. O trabalho, a carreira e os interesses pessoais tornam-se preponderantes e percebe-se que as ideias e ações das pessoas colidem e/ou coincidem na vida política das organizações. Quando os interesses colidem, surge o conflito, seja por uma divergência de interesse real ou imaginada. Na tentativa de resolver os conflitos, que muitas vezes tornam-se institucionalizados, o poder torna-se um meio de influência na busca de determinados interesses (MORGAN, 2000). O político, o afetivo e criatividade passam a ter lugar dentro da vida organizacional, animada por paixões, interesses, conflitos e poder.

Entretanto, é necessário reconhecer as organizações além de estruturas políticas geridas pela racionalidade técnica. Assim, uma nova abordagem das organizações passou a considerá-las como um meio cultural com elementos simbólicos e imaginários. A organização passou a ser entendida, também, como uma comunidade expressiva repleta de significados que não podem ser compreendidos por uma análise linear e racional. A cultura nas organizações necessitou ser tratada como um processo de construção da realidade organizacional, na qual os indivíduos colocam em constante interação a sua cultura com a cultura da organização, que passou a ser vista como lugar de desejos, frustrações, realizações, humanizações e cooptações.

A afetividade entra no contexto organizacional e o indivíduo necessita ser compreendido como agente social, capaz de fazer seus elementos simbólicos circular na organização. Estes elementos simbólicos não se restringem a apenas objetos de consumo, como obras de arte, livros, gastronomia, cinema, mas englobam as noções de simbólico de forma muito mais ampla, contemplando, por exemplo, os mitos e os ritos de uma sociedade como símbolos que, de alguma maneira, geram uma relação de significação ${ }^{28}$ entre os indivíduos.

Sob esta perspectiva organizacional contemporânea, na qual os sujei-

28

Por significação entende-se a sensação que elementos simbólicos podem causar no indivíduo que se relaciona com o que é difundido ou comunicado. Esta significação pode ser simples, como um entendimento denotativo, ou ainda pode ser complexo, na medida em que esta significação causa vários efeitos interpretativos com base na relação afetiva e cultural de cada sujeito. Pensa-se nesta significação individual, uma vez que um mesmo ato comunicativo pode causar diferentes interpretações e percepções, mesmo que os indivíduos tenham a mesma formação e pertençam ao mesmo grupo. 
tos que a compõem não são fixos (HALL, 2001), muito menos estáveis e estão em busca de seus objetivos pessoais, é necessário compreender que a comunicação de uma organização pode se (re)estruturar por laços sociais através da afetividade e das manifestações culturais e criativas dos elementos simbólicos que circulam entre os indivíduos organizacionais. Assim, o processo de comunicação organizacional torna-se o grande potencializador das afetividades através das relações de trabalho.

Segundo Wolton (2010), ontem, o laço social dizia respeito às relações entre estruturas sociais e culturais relativamente estáveis, e hoje, tudo está em interação baseada em um vínculo social mais dinâmico e frágil. O entendimento de comunicação para este estudo, é sobre a comunicação que possibilita entrar em contato com o outro, expressar, falar, compartilhar, e que pode acontecer por vários motivos, mas principalmente culturais e afetivos. Wolton (2010) distingue três razões principais, frequentemente misturadas e hierarquizadas, conforme as circunstâncias, que estimulam os sujeitos a entrar em contato com alguém:

Primeiramente compartilhar. Cada um tenta se comunicar para compartilhar, trocar. É uma necessidade humana fundamental e incontrolável. Viver é comunicar e realizar trocas com os outros do modo mais frequente e autêntico possível. Depois vem a sedução, que é inerente a todas as relações humanas e sociais. Enfim, a convicção, ligadas a todas as lógicas de argumentação utilizadas para responder a objeções. (WOLTON, 2010, p. 17)

Com isto percebe-se que os laços sociais criados podem manter ligados em uma organização grupos e indivíduos, uma vez que estejam, fortemente relacionados pela cultura e pelos afetos. Geertz (1989) aponta que é necessário atentar para o comportamento dos sujeitos e fazê-lo com exatidão, pois é através do fluxo de comportamento - ou mais precisamente da ação social - que as formas culturais encontram articulação. Quaisquer que sejam, ou onde quer que estejam, os elementos que constituem determinada cultura necessitam ser analisados tendo como base a relação que estabelecem em meio às ações sociais que se desenvolvem em determinado contexto.

No que se refere as afetividades, estas são muitas discutidas na área da educação por teóricos como Piaget, Vygotsky e Wallon. Mas a mesma, também, tem sua relevância dentro do contexto organizacional. O afeto é considerado a energia que move as ações dos seres humanos, pois sem a 
A comunicação organizacional cultural e afetiva: uma reflexão das relações de trabalho criativa no contexto da economia criativa

troca, o calor e a afabilidade não há motivação nem interação entre os sujeitos, o que pode dificultar o desenvolvimento da criatividade e da inteligência. A afetividade é necessária para a vida e essencial para a construção de relações criativas entre os indivíduos. Para Piaget (apud LA TAILLE, 1992), o desenvolvimento da criatividade e da inteligência humana só se efetiva a partir das interações sociais.

O homem é um ser essencialmente social, impossível, portanto, de ser pensado fora do contexto da sociedade em que nasce e vive. Em outras palavras, o homem não social, o homem considerado como uma molécula isolada do resto de seus semelhantes, o homem visto como independente das influências dos diversos grupos que frequenta, o homem visto como imune aos legados da história e da tradição, este homem simplesmente não existe (PIAGET apud LA TAILLE, 2003, p. 11).

Assim sendo, cresce a necessidade da reflexão sobre a importância da relação de pessoas criativas nos contextos organizacionais, a partir do entendimento das diferentes formas de manifestações culturais, ou através dos elementos simbólicos que circulam, interagem, criam e recriam identidades, servindo de pano de fundo como elemento norteador de suas ações e seus princípios criativos. Isto por que considera-se cada indivíduo como único interagindo na multiplicidade de contextos (CANCLINI, 2007, MORIN 2008). Assim, cada sujeito é ao mesmo tempo singular e universal. De acordo com Freitas (2000, p. 87), "somos ao mesmo tempo um individual e um coletivo, um sozinho e uma multidão, um ninguém e um todo-mundo, que se apresenta e representa nas relações múltiplas do cotidiano". Mesmo sendo individual e/ou coletivo, mesmo agindo na instância grupal e/ou individual, os sujeitos tornaram-se coadjuvantes do contexto organizacional contemporâneo através de suas afetividades e sua cultura.

\section{ECONOMIA CRIATIVA: AS RELAÇÕES DE TRABALHO COMO FORMA DE CRIATIVIDADE ORGANIZACIONAL}

Assiste-se, atualmente, a uma mudança da Divisão Internacional do Trabalho, em que a perspectiva é de predomínio da dimensão financeira sob a dimensão social. A busca de novos mercados e a procura por menores custos de produção para aumentar o lucro das organizações contribuíram para deslocar os processos produtivos, especialmente para os países semiperifé- 
ricos. Segundo Pochmann (2001, p. 26), esse processo de investimento de capital em países de periferia ou semiperiféricos constituiu-se em uma alternativa de "multicolonialismo renovado". Assim, as multinacionais transformaram-se em organizações transnacionais, ainda maiores e mais poderosas, com capacidade de considerar o mundo inteiro como espaço relevante para as suas decisões de investimentos e produção, reorganizando o processo produtivo diante de grandes extensões territoriais. Ianni (1999, p. 19) usa a expressão "Fábrica Global” como metáfora de uma realidade que se instalou além de toda e qualquer fronteira, articulando capital, tecnologia, força de trabalho, divisão do trabalho social e outras forças produtivas.

O objetivo dessas organizações transnacionais foi de se manter o mais livre possível de investimentos de longa duração, buscando cada vez mais ofertas de governos nacionais para o rebaixamento de custos e financiamentos subsidiados, com a intenção de explorar rapidamente as oportunidades lucrativas de investimentos, abrindo e fechando quantas organizações fossem necessárias (SANTOS, 2005). Para Pochmann (2001), este processo acabou provocando rebaixamento ainda maior do custo do trabalho, com contratos especiais e ampliação da jornada, ocasionando a desregulamentação do mercado de trabalho e a sobreposição total do processo econômico sobre o social.

O movimento de deslocamento de indústrias para a periferia e a produção de bens em alta escala, com a rotinização das tarefas e simplificação tecnológica, acabaram por movimentar a estrutura ocupacional das organizações. É praticamente impossível separar os efeitos da Divisão Internacional do Trabalho de outras mudanças concomitantes que vêm ocorrendo nos contextos organizacionais, atingindo principalmente os trabalhadores e suas relações econômicas. Com isso, o mercado autorregulador da economia se movimenta novamente, e a dialógica entre relações sociais/culturais e econômicas torna-se ainda maior nas organizações. O antagonismo, que nunca deixou de existir, agora revigora-se.

Neste contexto dialógico entre o social/cultural e o econômico no meio organizacional, a economia criativa se coloca na pauta da pesquisa e com ela a abordagem do trabalho criativo ou das relações de trabalho criativas. Segundo Costa e Santos (2011), a matéria-prima da economia criativa está no conceito de criatividade construído ao longo das décadas e fundada em várias dimensões do fenômeno. Baseia-se na concepção individual de ideais 
A comunicação organizacional cultural e afetiva: uma reflexão das relações de trabalho criativa no contexto da economia criativa

gerados e pode ser modificada quando nasce da articulação entre as diferentes criatividades: científica, tecnológica, cultural e econômica.

A Unesco (2010) coloca a economia criativa como forma de impulsionar o crescimento econômico e representar uma alternativa para o desenvolvimento, especialmente por ter como matéria-prima a criatividade e poder utilizar características culturais e sociais de cada país/região como vantagens no desenvolvimento e produção de bens e serviços únicos competitivos. Em se tratando de possibilidades de desenvolvimento, a economia criativa, enquanto potencialidade competitiva, pode ser utilizada também nos contextos organizacionais e pode ser compreendida de acordo com a emergência do enlace entre cultura e economia nas organizações. Refere-se ao conjunto de elementos simbólicos, baseados na criatividade, no talento e na habilidade individual de seus sujeitos e incorporados no contexto organizacional com suas imbricações e importantes implicações na área da gestão, principalmente na potencialização de relações de trabalho criativas. Isto por que, de acordo com John Howkins (2001), a criatividade não é monopólio dos artistas, mas está presente nos cientistas, empresários, economistas, entre outros, pois eles têm a capacidade de criar algo novo, original, pessoal, significativo e real.

Porém, segundo Huws (2015) quando a maioria das pessoas fala de trabalho criativo, ou relações de trabalho criativas, no entanto, eles têm uma gama de tarefas que normalmente são aquelas atividade que envolvem "ter ideias" para novos produtos ou processos, adaptando os já existentes para novos propósitos ou criação de conteúdos midiáticos. Trabalhadores criativos parecem ser uma demanda como nunca antes vista. Porém, é necessário considerar que a criatividade também pode estar sujeita ao controle e à contestação de organizações que não abrem espaços para a interação e afetividade dos elementos simbólicos dos indivíduos organizacionais. Segundo Huws, "o truque do capitalismo é apropriar-se desta criatividade humana, a fim de criar um lucro que pode ser reinvestido para criar mais mercadorias, e mais lucro, de forma continuada (embora turbulenta) no processo de desenvolvimento. A expansão contínua é, portanto, uma das suas características essenciais" (2015, p. 86).

Algumas organizações, diante da necessidade de apropriação da criatividade, procuram desenvolver controles intensos, nas relações de trabalho, não se tornando lugares tão flexíveis como os sujeitos criativos gostariam de vivenciar as suas afetividades. Com isto a interação entre indivíduos e 
organização com a expressão e construção de si, através da identidade, criatividade e afetividade tem sido pouco investigado. Segundo Bendassolli e Andrade (2010) o significado do trabalho deve ser incorporada ao campo do conhecimento denominado microcomportamento organizacional que é formado por três dimensões: cognitiva (crenças, conhecimentos, ideias, pensamentos, representações e informações relacionadas a um objeto ou fenômeno), afetiva (valorações, emoções, motivações, sentimentos e necessidades) e comportamental (a ação propriamente dita). Dizer que o significado do trabalho é uma atitude implica, portanto, a consideração das manifestações culturais formadas sobre ele, dos afetos a ele ligados e do modo como a interação desses elementos repercute na ação no trabalho e principalmente da criatividade no trabalho.

\section{APONTAMENTOS}

As relações de trabalho nas organizações, para serem compreendidas como criativas, precisam pressupor a presença do outro que estabelece redes de comunicação e, com isso, laços de confiabilidade, sociabilidade e afetividade, construindo e reconstruindo valores tanto individuais como coletivos. Se trabalhar é trabalhar com o outro e comunicar é a interação, relação, troca, reelaboração, pode-se afirmar que ambos, comunicação e trabalho, atuam na construção dos conjuntos de valores que se renovam e/ou se cristalizam a cada escolha feita, a cada decisão do uso de si por si mesmo. O sujeito, enquanto ser social, cria e recria suas redes de relações e se apropria dos discursos que circulam no meio de trabalho (FIGARO, 2010), assim como, reelabora estes discursos imprimindo neles as suas referências de contexto criativo.

Sendo assim, apenas recentemente que as manifestações culturais, afetivas foram vistas como um manancial de geração de valor econômico nas relações de trabalho nos contextos organizacionais tendo por base suas possibilidades criativas. Porém, se faz necessário que as organizações compreendam esta ampla e complexa diferença entre economia criativa, de qualquer outro setor da economia, e de fato inclua a cultura e afetividade como componente para que as pessoas possam trabalhar a sua criatividade nos contextos organizacionais como uma forma de vida laboral com construção de sentido.

A comunicação nas relações de trabalho acontece pela interação e cons- 
A comunicação organizacional cultural e afetiva: uma reflexão das relações de trabalho criativa no contexto da economia criativa

trução de sentido dos sujeitos, e com isto quer-se dizer que nem sempre estas relações de trabalho seguem a lógica estabelecida pelos discursos, objetivos, valores e elementos simbólicos e culturais da organização, mas também os discursos, valores, objetivos e elementos simbólicos e culturais dos indivíduos criativos que estão em interação e relação na organização e imprimem nesta a sua criatividade. A comunicação nas relações de trabalho nas organizações torna-se palco de constantes construções e reconstruções de sentidos, e consequentemente na constituição e reconstituição da criatividade dos sujeitos.

Na medida em que as economias mundiais se tornam cada vez mais competitivas e produtivas, as chaves do seu sucesso econômico passam a ser a sua genialidade e as habilidades individuais, sendo a criatividade um processo que questiona os limites e os pressupostos estabelecidos nas relações de trabalho. Com isto, assumir e compreender o livre fluxo das ideias criativas nos contextos organizacionais é avançar de uma forma sistemática para que as relações de trabalho se tornem um método de fazer as coisas com relação com o outro de forma que a criatividade impulsione a inovação e a inovação impulsiona mudanças. A criatividade fornece meios de expressão individual e uma oportunidade de compartilhar e trabalhar conjuntamente com o outro, dissolvendo grande parte da divisão tradicional do trabalho existente.

Pensar a comunicação apenas como estratégia de gestão de determinada organização, no contexto contemporâneo, é um desafio que precisa ser ultrapassado, superando a racionalidade instrumentalizada. É necessário que se busque alternativas criativas, inovadoras e dinâmicas de colocar o ser humano em pauta nos contextos organizacionais, valorizando a capacidade criadora dos indivíduos, sem desprezar a subjetividade e a afetividade. 


\section{REFERÊNCIAS}

ANZIEU, D e MARTIN, J-Y. La dinámica de los grupos pequeños. Buenos Aires: Editorial Kapelusz , 1971.

BENDASSOLLI. Pedro, ANDRADE, Jairo Eduardo Borges. Significado do trabalho nas indústrias criativas. RAE. São Paulo v. 51 n. 2 mar./abr. 2010

CANCLINI, Nestor Garcia. Diferentes, desiguais e desconectados: mapas de interculturalidade. Rio de Janeiro: Editora UFRJ, 2007.

COSTA, Armando; SOUZA-SANTOS, Elson Rodrigo. Economia criativa: novas oportunidades baseadas no capital intellectual. Economia \& Tecnologia - Ano 07, Vol. 25 - Abril/ Junho de 2011.

ENRIQUEZ, Eugène. A organização em análise. Petrópolis, RJ: Vozes 1997.

FIGARO, Roseli. Relações de comunicação no mundo do trabalho e a comunicação das organizações. IN:KUNSCH, Margarida. A comunicação como fator humano nas organizações. São Caetano do Sul, SP: Difusão editora, 2010.

FLORIDA, Richard. Ascenção da classe criativa. L\&PM Editora, 2002.

FREITAS, Maria Ester. Cultura organizacional. Rio de Janeiro: Editora FGV, 2000.

GEERTZ, Clifford. A interpretação das culturas. Rio de Janeiro: LTC, 1989.

HALL, Stuart. A identidade Cultural na pós-modernidade. Rio de Janeiro: DP\&A, 2001.

HOWKINS, J. The creative economy: how people make money from ideas. London: Penguin Press, 2001.

HUWS. Ursula. A ignição no motor: trabalhadores criativos na economia global. In: PARÁGRAFO. JAN./JUN.2015 V.1, N. 3 (2015) ISSN: 2317-4919

IANNI, Octavio. Teorias da globalização. 5ed. Rio de Janeiro: Civilização Brasileira, 1999. MORIN, Edgar. Introdução ao pensamento complexo. Lisboa: Instituto Piaget, 1991. MORIN, Edgar. O Método IV: as ideias. Porto Alegre: Sulina, 2008.

MORGAN, Gareht. Imagens da Organização. São Paulo: Atlas, 2000.

LAPASSADE, Georges. Grupos, organizações e instituições. Rio de Janeiro: F Alves, 1989.

LA TAILLE, Yves de; OLIVEIRA, Marta Kohl; DANTAS, Heloysa. Piaget, Vygotsky, Wallon: teorias psicogenéticas em discussão. São Paulo: Summus, 1992.

POCHMANN, M. O emprego na globalização. São Paulo: Boitempo Editorial, 2001.

SANTOS, Boaventuta. Os processos de globalização. IN: SANTOS, Boaventuta. A globalização e as ciências sociais. 3ed. São Paulo: Cortez 2005

SROUR, Robert Henry. Poder, cultura e ética nas organizações. Rio de Janeiro: Campus, 1998.

UNESCO. Creative economy: report 20_0. Nova York: United Nation, 20_0.

WOLTON, Dominique. Informar não é comunicar. Porto Alegre: Editora Sulina, 2010. 
A comunicação organizacional cultural e afetiva: uma reflexão das relações de trabalho criativa no contexto da economia criativa

\section{Caroline Delevati Colpo}

Atualmente é professora dos Cursos de Comunicação Social da Universidade Feevale - Novo Hamburgo/RS. Doutora em Comunicação Social: linha de pesquisa Práticas Profissionais e Processos Sociopolíticos nas Mídias e na Comunicação das Organizações - PUC/RS. Mestre em Desenvolvimento Regional - UNISC. Graduada em Relações Públicas - UFSM. Já atuou como professora da Unochapecó/SC e como professora substituta na UFSM. 
CADERNOS DE COMUNICAÇÃO

V.19, N.2, JUL-DEZ 2015

RECEBIDO EM: 19/11/2015

APROVADO PARA PUBLICAÇÃO: 24/11/2015 